2. Miller DC. Valve-sparing aortic root replacement in patients with the Marfan syndrome. J Thorac Cardiovasc Surg. 2003;125:773-8.

3. Grande-Allen KJ, Cochran RP, Reinhall PG, Kunzelman KS. Re-creation of sinuses is important for sparing the aortic valve: a finite element study. J Thorac Cardiovasc Surg. 2000;119:753-63.
4. Swanson M, Clark RE. Dimensions and geometric relationships of the human aortic valve as a function of pressure. Circ Res. 1974;35:871-82.

5. Kallenbach K, Hagl C, Walles T, Leyh RG, Pethig K, Haverich A, et al. Results of valve-sparing aortic root reconstruction in 158 consecutive patients. Ann Thorac Surg. 2002;74:2026-33.

\title{
Percutaneous repair of an ascending aortic pseudoaneurysm with a septal occluder device
}

Christopher B. Komanapalli, MD, ${ }^{a}$ Grant Burch, MD, ${ }^{b}$ Uttam Tripathy, MD, Matthew S. Slater, MD, and Howard K. Song, MD, ${ }^{a}$ Portland, Ore

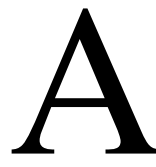

scending aortic ${ }^{1}$ pseudoaneurysms are rare complications of cardiovascular surgery. ${ }^{1}$ Repair of ascending aortic pseudoaneurysms in the past has required redo sternotomy and cardiopulmonary bypass for suture or patch repair. For patients who are poor surgical candidates, catheter-based interventions have been considered to repair this potentially lethal complication. Two cases of ascending aortic pseudoaneurysm have been previously reported in which catheter-based therapy was used., ${ }^{2,3}$ One described placement of a Fogarty balloon catheter to provide temporary occlusion of a pseudoaneurysm before surgical intervention. ${ }^{2}$ The other involved catheter-based delivery of thrombin into the pseudoaneurysm that resulted in thrombus propagation into the ascending aorta, leading to transient ischemic attack. ${ }^{3}$ Here we present the successful use of an Amplatzer septal occluder (AGA Medical Corp, Golden Valley, Minn) to exclude a pseudoaneurysm from the ascending aorta of a patient who was a poor candidate for operative intervention (Figure 1).

\section{Clinical Summary}

A 79-year-old woman underwent elective aortic valve replacement with a bioprosthetic valve at another institution. Her medical history was significant for aortic stenosis, atrial fibrillation, and congestive heart failure. Her postoperative course was complicated by postoperative hemorrhage requiring re-exploration, as well as prolonged intensive care unit stay because of respiratory and renal

\footnotetext{
From the Department of Surgery, Division of Cardiothoracic Surgery, a and the Department of Pediatrics, Division of Cardiology, ${ }^{\mathrm{b}}$ Oregon Health and Science University, Portland, Ore.

Received for publication Feb 10, 2005; accepted for publication Feb 24, 2005.

Address for reprints: Howard K. Song, MD, OHSU Division of Cardiothoracic Surgery, Mail Code: L353, 3181 SW Sam Jackson Park Rd, Portland, OR 97239 (E-mail: songh@ohsu.edu).

J Thorac Cardiovasc Surg 2005;130:603-4

$0022-5223 / \$ 30.00$

Copyright $\odot 2005$ by The American Association for Thoracic Surgery doi:10.1016/j.jtcvs.2005.02.044
}

failure. Five months after aortic valve replacement, the patient presented with shortness of breath and hemoptysis. A computed tomographic scan demonstrated a large pseudoaneurysm originating from

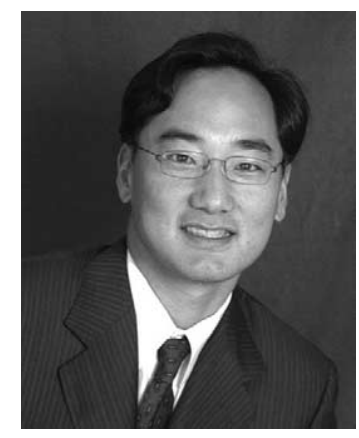

Dr Song the mid-ascending aorta measuring $3.8 \times 6.5 \mathrm{~cm}$ (Figure 2, A). Laboratory studies revealed normal white blood cell counts, and blood cultures obtained on admission were negative. Transesophageal echocardiography confirmed the presence of the lesion and demonstrated blood flow into the sac through a narrow communication with the ascending aorta. A long discussion was held with the patient and her family regarding the risks and benefits of traditional operative repair given the patient's age, heart failure,



Figure 1. Photograph of the Amplatzer septal occluder in its deployed shape. 



Figure 2. Computed tomographic scans pre- and post-procedure. A, The pre-procedure study demonstrates a large pseudoaneurysm originating from the mid-ascending aorta. $P$, Pseudoaneurysm; $A$, ascending aorta; arrow, pseudoaneurysm neck. $B$, The follow-up study shows good device placement and exclusion of the pseudoaneurysm cavity from the ascending aorta. $A$, Ascending aorta; arrow, septal occluder.

and deconditioning from the previous operation. A recommendation was made to attempt exclusion of the pseudoaneurysm with an Amplatzer septal occluder device.

At the time of the procedure, an $8 \mathrm{~F}$ guiding catheter was advanced through the aortic wall defect into the pseudoaneurysm; its internal slip catheter was exchanged for a 5-mm Amplatzer septal occluder device, which had been preloaded to its delivery cable; and the distal (left atrial) disc was delivered into the pseudoaneurysm. The device was pulled back against the aneurysm wall, and the proximal (right atrial) disc was delivered into the ascending aorta. Device placement was confirmed by angiography, and the device was deployed. The patient tolerated the procedure well, and there were no complications. The patient was maintained on clopidogrel for 6 weeks to reduce stroke risk until endothelialization of the device had occurred.

At 6 months' follow-up, the patient remains well. A follow-up computed tomographic scan shows good device placement and exclusion of pseudoaneurysm cavity from the ascending aorta (Figure 2, B). Transthoracic echocardiography confirms no flow into the pseudoaneurysm.

\section{Discussion}

Traditional management of ascending aortic pseudoaneurysms that arise as a complication of cardiovascular surgery has been redo sternotomy and open repair of the pseudoaneurysm with either suture or patch closure. ${ }^{1,4}$ Patients with multiple comorbidities or significant overall decrease in physical condition might be better served with catheter-based interventions. Previous attempts either have been palliative ${ }^{2}$ or have resulted in thromboembolic complications. ${ }^{3}$ Here we describe the successful use of the Amplatzer septal occluder device to exclude a pseudoaneurysm from the ascending aorta. This procedure avoided surgical morbidity and thromboembolic complications and has effectively treated the pseudoaneurysm at midterm follow-up. Percutaneous pseudoaneurysm repair with a septal occluder should be considered in selected patients for whom redo sternotomy and traditional open repair carries significant risk.

\section{References}

1. Dumont E, Carrier M, Cartier R, Pellerin M, Poirier N, Bouchard D, et al. Repair of aortic false aneurysm using deep hypothermia and circulatory arrest. Ann Thorac Surg. 2004;78:117-21.

2. Hatfield DR, Fried AM, Ellis GT, Mattingly WT Jr, Todd EP. Intraoperative control of an ascending aortic pseudoaneurysm by Fogarty balloon catheter: a combined radiologic and surgical approach. Radiology. 1980;135:515-7.

3. Lin PH, Bush RL, Tong FC, Chaikof E, Martin LG, Lumsden AB. Intra-arterial thrombin injection of an ascending aortic pseudoaneurysm complicated by transient ischemic attack and rescued with systemic abciximab. J Vasc Surg. 2001;34:939-42.

4. Sullivan KL, Steiner RM, Smullens SN, Griska L, Meister SG. Pseudoaneurysm of the ascending aorta following cardiac surgery. Chest. 1988;93:138-43. 